\title{
نَ CEREUS
}

\section{Aplicação da hibridização genômica comparativa no diagnóstico e prognóstico das doenças oncológicas}

\section{Application of comparative genomic hybridization in the diagnosis and prognosis of oncological diseases}

Caroline Christine Pincela da Costa ${ }^{1}$, Fábio Silvestre Ataides², Sandra Ribeiro de Morais ${ }^{3}$, Jacqueline Andréia Bernardes Leão-Cordeiro ${ }^{4}$, Cesar Augusto Sam Tiago Vilanova-Costa ${ }^{5}$, Antônio Márcio Teodoro Cordeiro Silva ${ }^{6}$

\section{RESUMO}

O câncer é uma patologia grave representada pela proliferação celular maligna e representada, especialmente, por seus marcadores genéticos e moleculares e as alterações citogenéticas são características do câncer. A predisposição genética e interação com o meio ambiente, bem como os mecanismos genéticos que podem desencadear um processo oncológico, como a perda de heterozigose em genes supressores de tumor somam-se na gênese de tal processo. Estas alterações remetem à instabilidade genômica como fator de progressão da oncogênese, que ocorre mediante acúmulo de danos genéticos adicionais. A array-CGH é uma técnica genômica que auxilia na identificação de genes candidatos à oncogênese, que avalia ganhos e/ou perdas de material genético em níveis submiscroscópicos, e identifica seus achados como possíveis alterações ou variações no número de cópias (CNAs/CNVs, respectivamente), bem como suas relações com resposta à drogas e prognóstico.

Palavras-chave: Hibridização genômica comparativa. Aberrações cromossômicas. Oncogênese.

\section{ABSTRACT}

Cancer is a serious pathology represented by a malignant cell proliferation and characterized especially by its genetic and molecular markers and cytogenetic changes. Genetic predisposition and interaction with the environment, as well as the genetic mechanisms that can trigger an oncological process, such as the loss of heterozygosity in tumor suppressor genes, add up to the cancer genesis and development. These changes refer to genomic instability as a factor of progression of oncogenesis, which occurs through the accumulation of additional genetic damages. The CGH array is a genomic technique that assists in the identification of candidate genes for oncogenesis, which evaluates gains and / or losses of genetic material, and identifies their findings as possible changes or variations in the number of copies (CNAs / CNVs, respectively), as well as their relationship to drug response and prognosis.

Keywords: Comparative genomic hybridization. Chromosomal aberrations. Oncogenesis.
${ }^{1}$ Mestranda no Programa de PósGraduação Genética e Biologia Molecular, Instituto de Ciências Biológicas (ICB), Universidade Federal de Goiás (UFG).

2,3Doutor(a), Instituto de Ciências da Saúde (ICS), Universidade Paulista (UNIP), Flamboyant.

${ }^{4}$ Doutora, Faculdade de Enfermagem (FEN), Universidade Federal de Goiás (UFG).

${ }^{5}$ Doutor, Laboratório de Biologia Tumoral e Oncogenética, Hospital Araújo Jorge, Associação de Combate ao Câncer de Goiás (ACCG).

${ }^{6}$ Doutor, Curso de Medicina, Escola de Ciências Médicas, Farmacêuticas e Biomédicas (EMFB), Pontifícia Universidade Católica de Goiás (PUC Goiás).

E-mail: marciocmed@gmail.com 


\section{INTRODUCĀO}

No contexto genético, grande proporção das neoplasias desenvolve-se por mutações somáticas adquiridas no decorrer da vida, que podem surgir espontaneamente, sejam por exposição a agentes mutagênicos ou por erros de replicação (INCA, 2018), e, nesse caso, o poder de reparação de genes supressores de tumor é crítico, pois requer interação complexa entre diferentes vias de reparo de DNA (VODICKA et al., 2015).

Os rearranjos cromossômicos estão diretamente relacionados com a etiologia da doença (CAMACHO et al., 2017), e assim, as técnicas citogenéticas moleculares, como a hibridização genômica comparativa $(\mathrm{CGH})$, têm sido empregadas para avaliar genes-alvo de alguma anormalidade cromossômica (DUTTA, 2014; LIEHR et al., 2014). A CGH é uma técnica com grande sensibilidade, que pode estar associada ao uso de microarranjos de DNA para identificar mudanças no número de cópias de DNA em todo o genoma, mapeando e determinando os locais de doença, avaliando também a predisposição dos indivíduos de desenvolvê-la (DUTTA, 2014).

As mudanças no número de cópias são variações que afetam muitos pares de bases, resultando em variações/alterações no número de cópias (CNVs/CNAs, respectivamente). Ambas as mudanças no número de cópias são ganhos ou perdas de material genético que envolvem rearranjos desequilibrados, podendo variar quanto ao tamanho de um quilobase $(\mathrm{Kb})$ a grandes megabases (Mb) (SHAlKH, 2017). Tanto as CNVs como as CNAs são tipos de mutações que diferem entre si quanto a origem, sendo as CNVs de origem meiótica, disposta em todo genoma e as CNAs são mudanças somáticas restritas ao tecido ou órgão acometido, e tais mutações são uma característica primária das células cancerígenas quando analisadas a nível molecular (Banerjee \& Shah, 2013). As CNVs, principalmente, são extraordinárias fontes de variabilidade genética e muitas vezes não influenciam no fenótipo, sendo tão importantes quanto a diversidade genômica dada por polimorfismos de nucleotídeo único (SNP) (WISZNIEWSKA et al., 2014), abrangendo até $12 \%$ do genoma (ZHANG et al., 2016).

Atualmente, a melhor técnica para identificar as CNVs e as CNAs (KRIJGSMAN et al., 2014), são as análises por microarranjos como array-CGH, que não detecta rearranjos balanceados (SHAIKH, 2017; CHEUNG \& BI, 2018; NOWAKOWSKA, 2017). A array-CGH é uma técnica derivada da hibridização in situ por fluorescência (FISH) e foi inicialmente desenvolvida como uma ferramenta para a pesquisa de desequilíbrios cromossômicos no câncer (KALLIONIEMI et al., 1992). A sobreposição de marcadores CGH+SNP-array 
COSTA, C. C. P.; ATAIDES, F. S.; MORAIS, S. R.; LEÃOCORDEIRO, J. A. B.; VILANOVA-COSTA, C. A. S. T.; SILVA, A. M. T. C.

Aplicação da hibridização genômica comparativa no diagnóstico e prognóstico das doenças oncológicas.

ampliam a cobertura de detecção das alterações cromossômicas, permitindo a genotipagem, análise de mosaicismo, perda de heterozigose e dissomias uniparentais (WISZNIEWSKA et al., 2014; CHEUNG \& BI, 2018). Desta forma, o objetivo deste trabalho foi realizar uma revisão bibliográfica a respeito da utilização da hibridização genômica comparativa como método auxiliar no diagnóstico e prognóstico em diferentes neoplasias.

\section{MATERIAIS E METODOS}

A metodologia utilizada nesta pesquisa foi uma revisão bibliográfica descritiva, sendo que a busca pelos artigos foi realizada no período de junho/julho de 2018, e as bases de dados usadas para a pesquisa foram LILACS, PubMed e SciELO. Os critérios de inclusão foram artigos em português, inglês ou espanhol, publicados em periódicos nos últimos cinco anos e os critérios de exclusão foram revisões bibliográficas, dissertações e teses, além de artigos cujo tema ou a metodologia utilizada não permitissem obter boas evidências acerca do tema proposto no trabalho.

Para a pesquisa, foi utilizada a combinação das palavras chaves: "array comparative genomic hybridization" ou "array-CGH" e "Cancer" (Câncer), considerados descritores no DeCS (Descritores em Ciências de Saúde) e MeSH (Medical Subject Headings).

Como resultado da busca, foram inicialmente encontrados 58 artigos na base de dados PubMed, 11 na base de dados LILACS e 2 na SciELO. Com os critérios de exclusão, 38 artigos foram selecionados e lidos integralmente, sendo 36 do PubMed e 1 da SciELO e LILACS. Após leitura na íntegra 31 artigos se tornaram objeto de estudo, sendo 30 artigos foram utilizados do PubMed, e 1 da SciELO e LILACS (mesmo artigo em ambas as bases).

\section{RESULTADOS E DISCUSSĀO}

\subsection{LEUCEMIAS}

As leucemias são exemplos clássicos dos recorrentes rearranjos cromossômicos no câncer. Sendo assim, uma inserção de novo detectada em um caso de leucemia mielóide aguda - ins(18;5)(q21.1;q31.2q35.1) - foi caracterizada por três microdeleções - 5q31.2, 5q35.1q35.2 e 18q12.3q21.1 - e uma microamplificação - 12q21.1, em cromossomos que 
COSTA, C. C. P.; ATAIDES, F. S.; MORAIS, S. R.; LEÃOCORDEIRO, J. A. B.; VILANOVA-COSTA, C. A. S. T.; SILVA, A. M. T. C.

Aplicação da hibridização genômica comparativa no diagnóstico e prognóstico das doenças oncológicas.

foram relacionados com uma rápida e desfavorável progressão da doença (KJELDSEN, 2014). Outro rearranjo comum, que implica em um prognóstico ruim em distúrbios mielóides, envolve o gene MECOM. A análise de um rearranjo envolvendo esse gene, situado no locus 3q26.2, demonstrou uma translocação não balanceada envolvendo as regiões $\mathrm{t}(3 ; 7)(q 26 ; q 21)$, com um cariótipo raro contendo três cópias do gene MECOM, que quando em alta expressão gênica é associada à redução da sobrevida de pacientes adultos e pediátricos em distúrbios mieloproliferativos (MATOS et al., 2018).

\subsection{CAVIDADE ORAL}

De acordo com um trabalho realizado com pacientes diagnosticados com carcinoma de células escamosas (CCE) da cavidade oral na Índia e Sri Lanka, mais de 50\% dos casos (16/24) apresentavam deleções em 1q21, sendo uma região que engloba genes da família S100, principalmente S100A14, que são usados como biomarcadores moleculares por estarem envolvidos em diferentes desenvolvimentos oncológicos e associados as deleções de 1q21 (LUNDE et al., 2014). A identificação de CNAs em CCE da cavidade oral pode ser relacionado com parâmetros e desfechos clínicos, pois a amplificação das regiões 7p, 8q, 9p e 11q nos genes CCND1, EGFR, TPM2 e LRP12, foram observados em casos com uma baixa sobrevida de pacientes com esse tipo de câncer (VINCENTCHONG et al., 2017).

O estudo dos genes envolvidos nos processos oncológicos permitiu analisar, principalmente, o perfil de diversos oncogenes e genes supressores de tumor. $\mathrm{O}$ gene EGFR, envolvido em CCE da cavidade oral, relatado por Vicent-Chong et al. (2017), não foi observado como alteração nos pacientes analisados por Lunde et al. (2014). O mesmo aconteceu com os genes TPM2 e LRP12, descritos como genes de papel crítico na oncogênese dos CCE da cavidade oral (VINCENT-CHONG et al., 2017). Entretanto, o gene CCND1, membro da família gênica $S 100$ obteve mudanças no número de cópias nos estudos de ambos autores (LUNDE et al., 2014; VINCENT-CHONG et al., 2017).

\subsection{MAMA}

Algumas características genéticas relacionadas com suscetibilidade do câncer de mama são determinadas por variações patogênicas envolvendo os genes BRCA1, 
COSTA, C. C. P.; ATAIDES, F. S.; MORAIS, S. R.; LEÃOCORDEIRO, J. A. B.; VILANOVA-COSTA, C. A. S. T.; SILVA, A. M. T. C.

Aplicação da hibridização genômica comparativa no diagnóstico e prognóstico das doenças oncológicas.

BRCA2, PTEN, ATM, TP53 R337H CHEK2 (1100delC). Pacientes com câncer de mama com critérios negativos para o subtipo mama e ovário hereditários, bem como pacientes que não possuam alterações nos genes $B R C A 1$ e $B R C A 2$, devem considerar análises dos genes PTEN, ATM, TP53 R337H CHEK2 (1100delC), visto o alto envolvimento de tais genes com o câncer de mama (SILVA et al., 2014).

A análise das variações patogênicas em BRCA2 mostra uma sequência homóloga muita curta de três nucleotídeos (GTC) no ponto de ruptura, caracterizado por uma microhomologia (sequências homólogas muito curtas entre 2 - 15 pb) como a causa da duplicação e consequentemente responsável pela variação patogênica (CONCOLINO et al., 2017). O gene BRCA1 foi estudado por Toffoli et al. (2014) em neoplasias de mama triplo negativo, verificaram que cerca de $90 \%$ dos casos com BRCA1 mutado revelaram, por meio da array-CGH, ganhos de até $2.4 \mathrm{Mb}$ em seu locus (17q21.31), bem como de genes da região 17q25, que possui genes ligados à oncogênese.

Em tumores primários de mama com metástases, a pesquisa de CNAs revela um perfil mutacional, pela utilização de array-CGH e o Sequenciamento de Nova Geração (NGS) dos genes ERBB2 (17q12), CCND1 (11q13.3), FGFR1 (8p11.23), MYC (8q24) e PAK1 (11q14.1), caracterizado por mutações e amplificações dos genes $A K T 1, C D H 1$, ERBB2, GATA3, MLL3/KMT2C, PIK3CA e TP53, os quais abrigam tanto proto-oncogenes quanto genes supressores de tumor, possivelmente desencadeando um processo oncológico (BERTUCCl et al., 2016). Além disso, amplificações em 11q13, 8p11 e 8q24, nos genes mutados CCND1, FGFR1 e $M Y C$, respectivamente, são observados em pesquisas por CNAs em cânceres de mama, entretanto, associados à radiação entre sobreviventes de câncer infantil (YANG et al., 2015).

\subsection{OVÁRIO E ÚTERO}

No prognóstico do câncer de ovário, mudanças no número de cópias do gene NTRK3 podem predizer a resistência a platina, influenciando negativamente na terapia. De acordo com estudos realizados com pacientes diagnosticados com câncer de ovário, a diferença no número de cópias entre grupos sensíveis e resistentes à platina foi superior a 1,5 vezes, sendo que a amplificação de NTRK3 é comum em grupos sensíveis a platina, estando assim ligada a uma resposta favorável no tratamento quimioterápico (GE et al., 2017). 
COSTA, C. C. P.; ATAIDES, F. S.; MORAIS, S. R.; LEÃOCORDEIRO, J. A. B.; VILANOVA-COSTA, C. A. S. T.; SILVA, A. M. T. C.

Aplicação da hibridização genômica comparativa no diagnóstico e prognóstico das doenças oncológicas.

Em cânceres de colo do útero, são recorrentes alterações em 3q, 1p36.22 e em 1q22 envolvendo genes como TERC, CLDN1, PGD e PMF1. Os genes TERC e CLDN1 são importantes na apoptose celular, enquanto os genes $P G D$ e $P M F 1$ desempenham papéis importantes no desenvolvimento do câncer do colo do útero, atuando, por exemplo, no controle do ciclo celular, e assim podem tornar-se alvos terapêuticos (ZHANG et al., 2016; LEE et al., 2014).

Apesar de em ambos os trabalhos, ganhos em $3 q$ terem sido descritos como recorrentes, alguns genes, como o CLDN1 e o $P G D$, que possuem alta importância na transformação celular de células cancerígenas do colo do útero, não são encontrados alterados em todos os cânceres desse tipo. Deleções em PMF1, um gene supressor de tumor, não foram descritas em nenhum outro trabalho analisado (ZHANG et al., 2016; LEE et al., 2014).

\subsection{PULMÃO}

Diversas alterações no número de cópias são relatadas em neoplasias pulmonares. Em adenocarcinomas primários, deleções em 9p23, 6q16.3, 5p15.33 e 8q24.21-q24.3 foram recorrentes, sendo o gene MYC frequentemente encontrado com alterações (ZHU et al., 2014). Já em mesoteliomas, a região 9p21.3 frequentemente deletada, envolvendo o gene CDKN2, sendo também relatados ganhos nos genes ERBB2 em 17q21.1, FCRL4 em 1q21.1, e ZDHHC11 em 5p15.33, conhecidos por serem mutados ou envolvidos nesse tipo de câncer (KLORIN et al., 2013).

Em CCE de pulmão, várias mudanças de cópias foram relatadas recorrentemente envolvendo a região $3 q$, englobando diversos genes. Tendo em vista que tais mudanças podem auxiliar no prognóstico de cada paciente, estudos com pacientes diagnosticados com tal neoplasia e com ganhos de 3q27.1, 5p13.2 e 5p13.3 implicaram em um prognóstico favorável, entretanto os que obtiveram ganhos em 11q23.3, 11q13.1 e 14q32.3, e deleções de 3p21.3 e 9p21.3 tenderam a uma sobrevida menor (CAO et al., 2016).

Ganhos em 3q26-28, envolvendo o gene FXR1 também foram relacionados a resposta imunológica suprimida nesse tipo de câncer. Este gene codifica uma proteína de ligação ao RNA que controla a expressão de fator de necrose tumoral alfa (TNF- $\alpha$ ), um mediador chave da inflamação na defesa do hospedeiro contra infecção e nas doenças 
autoimunes, bem como várias citocinas ou quimiocinas associadas à resposta de células T como IL-6, CCL2 e CCL5. Os resultados indicam a região amplicon em 3q como potencial regulador da resposta imune atuando como possível alvo na imunoterapia (QIAN et al., 2015).

Perdas em 3q26-q29 também foram comuns e tal região envolve genes como CLDN1, EIF4G, EVI1, FXR1, PI3K, RAP2B, TBL1XR1, THPO e TP63. A região 3q28 engloba o gene TP63 que sintetiza a proteína p63, a qual foi reconhecida como marcador imunohistoquímico em CCE do pulmão e em outros sítios. O gene PI3K mostrou-se vital para o crescimento e sobrevivência de células cancerígenas e inibidores visando a sinalização deste proto-oncogene estão sendo estudados como um potencial alvo terapêutico (LEE et al., 2015).

Nos cânceres de pulmão e mesoteliomas, os cromossomos 3 e 5, foram alvos comuns de alterações no número de cópias, porém, genes diferentes estiveram envolvidos. Os dados encontrados por Zhu et al. (2014) relataram alterações envolvendo o gene CLPTM1 e o associaram com o risco de câncer de pulmão, e, por outro lado, Cao et al. (2016), Klorin et al. (2013) e Lee et al. (2015) não relataram CNAs envolvendo tal gene em nenhum dos pacientes dos estudos, ainda que ganhos nesse locus foram descritas.

\subsection{PÂNCREAS}

Em cânceres pancreáticos, amplificações em 19q13.2 e em 7q22.1, envolvendo os genes AKT2 e MCM7, e deleções homozigóticas em 1p32, 17p13.2 envolvendo os genes CDKN2C, CAMTA2 e PFN1, indicam que tais genes podem desenvolver um papel importante no câncer pancreático, onde amplificações em AKT2 foram associadas com o aumento da sensibilidade à droga Z-LLNle-CHO, sugerindo que o gene pode se transformar em um biomarcador favorecendo a aplicação de diferentes esquemas terapêuticos (LIANG et al., 2014). Em adenocarcinomas do ducto pancreático foram relataram ganhos no cromossomo 8 , envolvendo principalmente o gene $M Y C$, que também está relacionado com outros cânceres, desempenhando um papel importante em vias relevantes para a oncogênese bem como o controle do ciclo celular (RAUSCH et al., 2017). 
COSTA, C. C. P.; ATAIDES, F. S.; MORAIS, S. R.; LEÃOCORDEIRO, J. A. B.; VILANOVA-COSTA, C. A. S. T.; SILVA, A. M. T. C.

Aplicação da hibridização genômica comparativa no diagnóstico e prognóstico das doenças oncológicas.

É possível perceber um perfil heterogêneo de mudanças de cópias em cânceres pancreáticos, com discrepâncias em relação aos genes envolvidos em sua oncogênese, como é o caso do gene PFN1 e do cromossomo 8 em cânceres do ducto pancreático (LIANG et al., 2014; RAUSCH et al., 2017).

\subsection{CABEÇA E PESCOÇO}

Os glioblastomas são cânceres raros que acomentem, em sua maioria, pessoas da terceira idade. Análises de mudanças no número de cópias em glioblastomas de pacientes com mais de 40 anos revelam ganhos comuns no cromossomo 7 e 19 e perdas no cromossomo 10, envolvendo os genes EGFR e PTEN, respectivamente., enquanto pacientes mais jovens acometidos pela doença foram mais propensos a abrigar perdas nos cromossomos 3, 4q, 5p, 16p, 19q e 21q e ganhos em 1q, 4, 9q, 10p, 11q e 12p, resultado que sugeriu diferentes perfis genômicos em diferentes idades, implicando em diferentes estratégias de tratamento (RAMKISSOON et al., 2015).

Alterações genômicas estudadas em CCE de cabeça e pescoço mostram alterações frequentes no cromossomo 11. Genes como PAFAH1B2, FLI1, ETS1, MMP1, CCND1, ORAOV1, FADD, PPFIA1 e CTTN foram relatados em diversos estudos desse tipo de câncer, onde estão envolvidos com a progressão dos tumores de CCE de cabeça e pescoço (SINGCHAT et al., 2016).

De acordo com estudo feito por Hu et al. (2016), que incluiu19 amostras de casos avançados de CCE de cabeça e pescoço de pacientes da Província de Jilin, no nordeste da China, 14 amostras revelaram ganhos em 11q13, com superexpressão dos genes CTTN e CCND1, e uma correlação significativa entre os ganhos de número de cópias e os níveis de expressão de mRNA, o que sugere que a superexpressão desses genes resulte em proliferação celular e facilidade de invasões e metástases.

Em carcinomas ex-adenomas pleomórficos, as alterações no número de cópias relataram ganhos comuns em $3 q$ e $8 q$ e amplificações em 12q14.3 e 12q15, envolvendo genes como HMGA2, MDM2, WIF1, WHSC1L1, RG3, CDK4, que são relacionados ao câncer e podem ser os fatores promocionais de recidiva da doença (MARIANO et al., 2016). 


\subsection{INTESTINO}

Neoplasias intestinais revelaram com frequência mudanças no número de cópias de genes nos cromossomos 16 e 18. Em tumores neuroendócrinos primários e metastáticos de intestino delgado foram comuns perdas nas regiões 16q e 18p e ganhos nas regiões $7 q$ e 20q13, que envolvem genes "iniciadores do câncer" como: $C D H 4$, LAMA5, RPS21, KIAA1510, TNFRSF6B (M68, DcR3), RTEL, EEF1A2 e PTK6, KIAA0650, LPIN2 e EMILIN2. O gene EMILIN2 é um componente da matriz extracelular que suprime o crescimento de células cancerígenas e tem um papel sobrevivência celular e de apoptose (HASHEMI et al., 2013).

O perfil genômico de câncer de cólon também revelou variações de cópias nos cromossomos 16 e 18. De acordo com estudo de Broek et al. (2016), realizado com pacientes acometidos com câncer de cólon em estágios II e III, foram comuns, em ambos os estágios, perdas nas regiões cromossômicas 18q12.1 e 18q12.2, bem como mutações nos genes APC e TP53, ambos supressores de tumor. No cromossomo 16, o locus 16 13.3 foi o mais atigindo pelas mudanças de cópias, envolvendo ganhos no gene RBFOX1, ligado á uma pior sobrevida livre de recidivas da doença (MAMPAEY et al., 2015).

Os perfis genômicos de cânceres de cólon revelaram distintas alterações gênicas, como os ganhos em $8 q, 13$ e $20 q$ e perdas em 1p, 4, 8p, 17p e 18, entretanto genes da via MAPK (KRAS, NRAS, BRAF) também foram encontrados mutados (BROEK et al., 2016; MAMPAEY et al., 2015).

\subsection{BEXIGA}

Em cânceres de bexiga não invasivos foram comuns mudanças no número de cópias em locis que incluiam os genes FAM81A e PCSK6, localizados no cromossomo 15, demonstrando associação significativa com recorrência e progressão da doença. 0 gene PCSK6 relaciona-se com a regulação da proliferação e da progressão de tumores de mama e próstata e podem estar relacionados com o câncer de bexiga (YAMAMOTO et al., 2017). Também foram relatadas deleções homozigóticas em 9p21 incluindo os genes CDKN2A e CDKN2B, que são supressores de tumor (WEILANDT et al., 2014; CONCONI et al., 2016), ressaltando sua importância no desenvolvimento no câncer de bexiga. 
COSTA, C. C. P.; ATAIDES, F. S.; MORAIS, S. R.; LEÃOCORDEIRO, J. A. B.; VILANOVA-COSTA, C. A. S. T.; SILVA, A. M. T. C.

Aplicação da hibridização genômica comparativa no diagnóstico e prognóstico das doenças oncológicas.

Outros genes, como CCNE1, MYC, MDM2 e PPARG também foram relatados com mudanças de cópias, destacando-se o gene CCNE1, podendo ser considerado um potencial marcador prognóstico para o câncer de bexiga (CONCONI et al., 2016).

\subsection{CORIOCARCINOMAS}

Alterações no número de cópias em coriocarcionomas gestacionais e não gestacionais foram relatadas afetando todos os cromossomos, em ambos os tipos de coriocarcinomas. Os genes mais afetados por CNAs detectados em coriocarcinomas gestacionais foram NF-KB, TEC e PTEN. A CNA que mostrou significância clínica foi o ganho em 21p11.1, também observado em coriocarcinomas não gestacionais. O ganho de $104.6 \mathrm{~Kb}$ e a ausência de genes conhecidos nesta região sugerem que essa alteração é um número de cópia polimórfica (MELLO et al., 2017).

\subsection{ANGIOSSARCOMAS DE OSSO}

A oncogênese de angiossarcomas de osso foi relacionada com mudanças no número de cópias nos locus 1p36, 8q24 e 17q, amplificações em 2q e 17q, bem como de $5 q 35$, que inclui o gene MPK9. Foram relatadas amplificações nas regiões $8 q 24.2$ e 1p36, envolvendo os genes MYC e SKI, ambos proto-oncogenes que codificam para fatores da transcrição e que estão envolvidos em muitas vias de sinalização, onde a amplificação de proto-oncogenes pode estar relacionada a oncogênese (VERBEKE et al., 2015).

\subsection{NEUROBLASTOMAS}

O perfil genético de neuroblastosmas revelou deleções submicroscópicas em 3p26.3, com 2,54 Mb de tamanho, envolvendo os genes CNTN4, CNTN6 e CHL1. Os genes CNTN4 e CNTN6 respondem para moléculas de adesão de células neuronais, enquanto o gene CHL1 está envolvido em atividades cognitivas gerais, bem como algumas doenças neurológicas, sendo sua baixa expressão relacionada a um prognóstico desfavorável, com uma baixa sobrevida (PEZZOLO et al., 2017). 


\section{CONSIDERAÇÕES FINAIS}

As análises cromossômicas por microarranjos são técnicas com alta resolução e sensibilidade que permitem a análise de todo genoma, mas ainda assim, são majoritariamente utilizadas em concomitância com outras técnicas moleculares, como FISH, SKY (cariotipagem espectral multicolorida) ou PCR (reação em cadeia da polimerase) ou sequenciamentos, que determinam mutações, confirmam ou quantificam os achados.

As limitações da $\mathrm{CGH}$, como a incapacidade de identificar alterações cromossômicas balanceadas, é um dos principais motivos ao qual os autores optam pela associação das técnicas. Contudo, os mesmos relatam que os rearranjos equilibrados, principalmente as translocações, são seguidas de um rearranjo detectável por CMAs.

Observa-se na literatura um vasto acervo acerca das patologias que envolvem as mudanças no número de cópias, como autismo, deficiência intelectual e anomalias genéticas. Apesar de autores tratarem todas as mudanças de cópias como CNVs, desconsiderando CNAs, outros relatam que ambas se referem a mesma coisa, sendo diferenciadas por sua origem. Alguns autores referem-se as CNAs como CNVs somáticas e outros generalizam as variações, chamando-as de "copy number changes".

A array-CGH mostra-se como uma técnica de extrema sensibilidade e efetividade na avalição de ganhos e perdas genômicas bem como suas relações com resposta à drogas e prognóstico. Entretanto, no Brasil, permanece uma técnica onerosa e ainda muito restrita a pesquisa e a casos limitados, sendo necessário mecanismos de suporte financeiro para que mais pesquisas se desenvolvam e colaborem com diagnóstico, prognóstico e tratamento de doenças.

\section{REFERÉNCIAS}

BANERJEE, D.; SHAH, S. P. Distinguishing Somatic and Germline Copy Number Events in Cancer Patient DNA Hybridized to Whole-Genome SNP Genotyping Arrays. In: Ha G, Shah S. Array comparative genomic hybridization - protocols and applications. Estados Unidos: Human Press, 2013. p.355-372.

BERTUCCI, F.; FINETTI, P.; GUILLE, A.; et al. Comparative genomic analysis of primary tumors and metastases in breast cancer. Oncotarget, v. 7, n. 19, p. 27208-27219, 2016. 
BROEK, E. V. D.; KRIJGSMAN, O.; SIE, D. et al. Genomic profiling of stage II and III colon cancers reveals APC mutations to be associated with survival in stage III colon cancer patients. Oncotarget, v. 7, n. 45, p. 73876-73887, 2016.

CAMACHO, N.; LOO, P.V.; EDWARDS, S.; et al. Appraising the relevance of DNA copy number loss and gain in prostate cancer using whole genome DNA sequence data. PLOS Genetics, v. 13, n. 9, p. 1-28, 2017.

CAO, Y.; LIU, Y.; YANG, X.; et al. Estimation of the survival of patients with lung squamous cell carcinoma using genomic copy number aberrations. Clinical Lung Cancer, v. 17, n. 1, p. $68-74,2016$.

CHEUNG, S. W.; BI, W. Novel applications of array comparative genomic hybridization in molecular diagnostics. Expert Review of Molecular Diagnostics, v. 18, n. 6, p. 531-542, 2018.

CONCOLINO, P.; RIZZA, R.; HACKMANN, K.; et al. Identification and characterization of a new BRCA2 rearrangement in an italian family with hereditary breast and ovarian cancer syndrome. Molecular Diagnosis and Therapy, v. 21, n. 5, p. 539-545, 2017.

CONCONI, D.; SALA, E.; BOVO, G.; et al. Using copy number alterations to identify new therapeutic targets for bladder carcinoma. International Journal of Molecular Sciences, v. 17, n. 3, p. 1-10, 2016.

DUTTA, U.R. Precision in chromosome identification with leads in molecular cytogenetics: An illustrated review. Journal of Pediatric Genetics, v. 3, n. 1, p. 1-7, 2014.

GE, L.; LI, N.; LIU, M.; XU, N. Z.; WANG, M. R.; WU, L. Y. Copy number variations of neurotrophic tyrosine receptor kinase 3 (NTRK3) may predict prognosis of ovarian cancer. Medicine, v. 96, n. 30, p. 1-6, 2017.

HASHEMI, J.; FOTOUHI, O.; SULAIMAN, L.; et al. Copy number alterations in small intestinal neuroendocrine tumors determined by array comparative genomic hybridization. BMC Cancer, v.13, n. 1, p. 1-13, 2013.

HU, X.; MOON, J. W.; LI, S.; et al. Amplification and overexpression of CTTN and CCND1 at chromosome 11 q13 in esophagus squamous cell carcinoma (ESCC) of north eastern 
COSTA, C. C. P.; ATAIDES, F. S.; MORAIS, S. R.; LEÃOCORDEIRO, J. A. B.; VILANOVA-COSTA, C. A. S. T.; SILVA, A. M. T. C.

Aplicação da hibridização genômica comparativa no diagnóstico e prognóstico das doenças oncológicas.

chinese population. International Journal of Medical Sciences, v. 13, n. 11, p. 868-874, 2016.

Instituto Nacional de Câncer. Ministério da Saúde. Câncer. Rio de Janeiro; 2018 [acesso 29 de mar 2018]. Disponível em: http://www.inca.gov.br/conteudo_view.asp?id=322.

KALLIONIEMI, A.; KALLIONIEMI, O. P.; SUDAR, D.; et al. Comparative genomic hybridization for molecular cytogenetic analysis of solid tumors. Science, v. 258, n. 5083, p. 818-821, 1992.

KJELDSEN, E. A novel insertion ins(18;5)(q21.1;q31.2q35.1) in acute myeloid leukemia associated with microdeletions at 5q31.2, 5q35.1q35.2 and 18q12.3q21.1 detected by oligobased array comparative genomic hybridization. Molecular Cytogenetics, v. 7, n. 1, p. 1-11, 2014.

KLORIN, G.; ROZENBLUM, E.; GLEBOV, O.; et al. Integrated high-resolution array CGH and SKY analysis of homozygous deletions and other genomic alterations present in malignant mesothelioma cell lines. Cancer Genetics, v. 206, n. 5, p. 191-205, 2013.

KRIJGSMAN, O.; CARVALHO, B.; MEIJER, G. A.; STEENBERGEN, R. D. M.; YLSTRA, B. Focal chromosomal copy number aberrations in cancer- needles in a genome haystack. Biochimica et Biophysica Acta, v. 1843, n. 2014, p. 2698-2704, 2014.

LEE, E.; WOOK, J. M.; WANG, X.; KIM, C.; LI, S.; SHIN, B. K. Genomic copy number signatures uncovered a genetically distinct group from adenocarcinoma and squamous cell carcinoma in non-small cell lung cancer. Human Pathology, v. 46, n. 8, p. 11111120, 2015.

LEE, M.; NAM, E. S.; JUNG, S. H.; et al. 1p36.22 region containing PGD gene is frequently gained in human cervical câncer. Journal of Obstetrics and Gynaecology Research, v. 40, n. 2, p. 545-553, 2014.

LIANG, J. W.; SHI, Z. Z.; SHEN, T. Y.; et al. Identification of genomic alterations in pancreatic cancer using array-based comparative genomic hybridization. PLoS One, v. 9, n. 12, p. 1-17, 2014. 
LIEHR, T.; OTHMAN, M. A.; RITTSCHER, K.; ALHOURANI, E. The current state of molecular cytogenetics in cancer diagnosis. Expert Review of Molecular Diagnostics, v. 15, n. 4, p. 517-526, 2015.

LUNDE, M.L. S.; ROMAN, E.; WARNAKULASURIYA, S.; et al. Profiling of chromosomal changes in potentially malignant and malignant oral mucosal lesions from south and southeast Asia using array - comparative genomic hybridization. Anticancer Research, v. 11, n. 3, p. 127-140, 2014.

MAMPAEY, E.; FIEUW, A.; LAETHEM, T. V.; et al. Focus on 16p13.3 locus in colon cancer. PLoS One, v. 10, n. 7, p. 1-15, 2015.

MARIANO, F. V.; GIOVANETTI, K.; SACCOMANI, L. F. V.; et al. Carcinoma expleomorphic adenoma derived from recurrent pleomorphic adenoma shows important difference by array CGH compared to recurrent pleomorphic adenoma without malignant transformation. Brazilian Journal of Otorhinolaryngology, v. 82, n. 6, p. 687-694, 2016.

MATOS, R. R. C.; OTHMAN, M. A. K.; FERREIRA, G. M.; et al. Molecular approaches identify a cryptic MECOM rearrangement in a child with a rapidly progressive myeloid neoplasm. Cancer Genetics, v. 221, p. 25-30, 2018.

MELLO, J. B. H.; CIRILO, P. D. R.; MICHELIN, O. C.; et al. Genomic profile in gestational and non-gestational choriocarcinomas. Placenta, v. 50, p. 8-15, 2017.

MISHRA, S; WHETSTINE, J. R. Different facets of copy number changes: permanent, transient, and adaptive. Molecular and Cellular Biology, v. 36, n. 7, p. 1050-1063, 2016.

NOWAKOWSKA, B. Clinical interpretation of copy number variants in the human genome. Journal of Applied Genetics, v. 58, n. 4, p. 449-457, 2017.

PEZZOLO, A.; SEMENTA, A. R.; LERONE, M.; et al. Constitutional 3p26.3 terminal microdeletion in an adolescent with neuroblastoma. Cancer Biology \& Therapy, v. 18, n. 5, p. 285-289, 2017.

QIAN, J.; ZOU, Y.; WANG, J.; ZHANG, B.; MASSION, P. P. Global gene expression profiling reveals a suppressed immune response pathway associated with $3 q$ amplification in squamous carcinoma of the lung. Genomics Data, v. 5, p. 272-274, 2015. 
COSTA, C. C. P.; ATAIDES, F. S.; MORAIS, S. R.; LEÃOCORDEIRO, J. A. B.; VILANOVA-COSTA, C. A. S. T.; SILVA, A. M. T. C.

Aplicação da hibridização genômica comparativa no diagnóstico e prognóstico das doenças oncológicas.

RAMKISSOON, S. H.; BI, W. L.; SCHUMACHER, S. E.; et al. Clinical implementation of integrated whole-genome copy number and mutation profiling for glioblastoma. NeuroOncology, v. 17, n. 10, p. 1344-1355, 2015.

RAUSCH, V.; KRIEG, A.; CAMPS, J.; et al. Array comparative genomic hybridization of 18 pancreatic ductal adenocarcinomas and their autologous metastases. BMC Research Notes, v. 10, n. 1, p. 1-9, 2017.

SHAIKH, T.H. Copy Number Variation Disorders. Current Genetic Medicine Reports, v. 5, n. 4, p. 183-190, 2017.

SILVA, F. C.; LISBOA, B. C. G.; FIGUEIREDO, M. C. P.; et al. Hereditary breast and ovarian cancer: assessment of point mutations and copy number variations in Brazilian patients. BMC Medical Genetics, v. 15, n. 1, p. 1-11, 2014.

SINGCHAT, W.; HITAKOMATE, E.; RERKARMNUAYCHOKE, B.; et al. Genomic alteration in head and neck squamous cell carcinoma (HNSCC) cell lines inferred from karyotyping, molecular cytogenetics, and array comparative genomic hybridization. PLoS One, v. 11, n. 8, p. 1-22, 2016.

TOFFOLI, S.; BAR, I.; ABDEL-SATER, F.; et al. Identification by array comparative genomic hybridization of a new amplicon on chromosome $17 q$ highly recurrent in BRCA1 mutated triple negative breast cancer. Breast Cancer Research, v. 16, n. 1, p. 1-16, 2014.

VERBEKE, S. L. J.; JONG, D.; BERTONI, F.; et al. Array CGH analysis identifies two distinct subgroups of primary angiosarcoma of bone. Genes, Chromosomes \& Cancer, v. 54, n. 2, p. 72-81, 2015.

VINCENT-CHONG, V. K.; SALAHSHOURIFAR, I.; WOO, K. M.; et al. Genome wide profiling in oral squamous cell carcinoma identifies a four genetic marker signature of prognostic significance. PLoS One, v. 12, n. 4, p. 1-21, 2017.

VODICKA, P.; MUSAK, L.; FRANK, C. et al. Interactions of DNA repair gene variants modulate chromosomal aberrations in healthy subjects. Carcinogenesis, v. 36, n. 11, p. 1299-1306, 2015. 
COSTA, C. C. P.; ATAIDES, F. S.; MORAIS, S. R.; LEÃOCORDEIRO, J. A. B.; VILANOVA-COSTA, C. A. S. T.; SILVA, A. M. T. C.

Aplicação da hibridização genômica comparativa no diagnóstico e prognóstico das doenças oncológicas.

WEILANDT, M.; KOCH, A.; RIEDER, H.; et al. Target genes of recurrent chromosomal amplification and deletion in urothelial carcinoma. Cancer Genomics \& Proteomics, v. 11, n. 3, p. 141-154, 2014.

WISZNIEWSKA, J.; BI, W.; SHAW, C.; et al. Combined array CGH plus SNP genome analyses in a single assay for optimized clinical testing. European Journal of Human Genetics, v. 22, n. 1, p. 79-87, 2014

YAMAMOTO, Y.; SUEHIRO, Y.; SUZUKI, A.; et al. Germline DNA copy number variations as potential prognostic markers for non-muscle invasive bladder cancer progression.

Oncology Letters, v. 14, n. 1, p. 1193-1199, 2017.

YANG, X. R.; KILLIAN, J. K.; HAMMOND, S.; et al. Characterization of genomic alterations in radiation-associated breast cancer among childhood cancer survivors, using comparative genomic hybridization (CGH) arrays. PLoS One, v. 10, n. 3, p. 1-11, 2015.

ZHANG, W.; LI, W.; WANG, X.; et al. CLDN1 expression in cervical cancer cells is related to tumor invasion and metastasis. Oncotarget, v. 7, n. 52, p. 87449-87461, 2016.

Zhang, W.; Li, W.; Wang, X.; et al. CLDN1 expression in cervical cancer cells is related to tumor invasion and metastasis. Oncotarget, v. 7, n. 52, p. 87449-87461, 2016.

ZHU, H.; WONG, M. P.; TIN, V. High-resolution detection of recurrent aberrations in lung adenocarcinomas by array comparative genomic hybridization and expression analysis of selective genes by quantitative PCR. International Journal of Oncology, v. 45, n. 6, p. 2068-2076, 2014. 